\title{
A INTERNACIONALIZAÇÃO DA EDUCAÇÃO SUPERIOR E O PROGRAMA DE ESTUDANTES - CONVÊNIO DE PÓS-GRADUAÇÃO: CARACTERIZAÇÕES PRELIMINARES
}

\author{
THE INTERNATIONALIZATION OF UNDERGRADUTE EDUCATION AND THE \\ "PROGRAMA DE ESTUDANTES - CONVÊNIO DE PÓS-GRADUAÇÃO” PROGRAM: \\ PRELIMINARY FEATURING
}

\section{LA INTERNACIONALIZACIÓN DE LA EDUCACIÓN SUPERIOR Y EL PROGRAMA DE ESTUDIANTES - CONVENIO DE POST-GRADUACIÓN: CARACTERIZACIONES PRELIMINARES}

\author{
Camila Kroetz $^{1}$; Giovanna Pezarico ${ }^{2}$ Franciele Clara Peloso $^{3}$
}

\begin{abstract}
RESUMO
Analisar os movimentos contemporâneos da internacionalização da Educação Superior pressupõe compreendêlos como inseridos num pano de fundo complexo e implicados pelas relações de interculturalidade. Nesse sentido, o estudo tem como enfoque a internacionalização da Educação Superior no contexto da Cooperação SulSul (CSS), especificamente, no que concerne ao Programa de Estudantes-Convênio de Pós-Graduação (PECPG). Para tanto, tem por objetivo caracterizar e discutir elementos preliminares do Programa PEC-PG, bem como, compreender aspectos de caráter geopolítico. Trata-se de uma pesquisa qualitativa, de tipo descritivo, de análise documental. Os resultados demonstram que há grande procura por áreas de conhecimento que possuem maior ênfase na aplicação de técnicas e tecnologias voltadas ao mercado de trabalho. Além disso, verifica-se que o PEC-PG, historicamente, vinculou-se principalmente com países da América Latina, tendo como principal justificativa a facilidade de acesso e intercâmbio. Contudo, a partir de 2003 houve uma aproximação significativa entre Brasil e África, a partir da CSS, por decorrência de aspectos históricos e culturais semelhantes. A partir disso, observa-se a presença das ambições e justificativas da internacionalização da Educação Superior na CSS, como fortalecedor de aspectos sociais, políticos, econômicos e de CT\&I. O olhar sobre o Programa PEC-PG evidencia que este corrobora diretamente com as premissas da internacionalização da Educação Superior e das relações de interculturalidade atuando junto ao fortalecimento dos países envolvidos no qual o Brasil é um país de destaque por protagonizar uma posição privilegiada desta cooperação.
\end{abstract}

\section{PALAVRAS-CHAVE:}

Educação Superior. Internacionalização. Programa PEC-PG.

\section{ABSTRACT}

To analyze the contemporary tendencies of internationalization of Undergraduete Education requires to understand them inserted in a complex background and affected by intercultural relations. In this sense, this study focuses on the internationalization of Undergraduate Education in the context of Cooperação Sul-Sul (CSS), specifically, regarding to the Programa de Estudantes-Convênio de Pós-Graduação (PEC-PG). For this purpose, the main objective is to characterize and discuss the preliminary elements of the PEC-PG Program, as

1 Graduação em Geografia Bacharelado pela UNICENTRO e em Geografia Licenciatura pela ULBRA. Mestranda em Desenvolvimento Regional pela UTFPR.

${ }^{2}$ Doutora em Tecnologia. Docente do PPGDR/PPGA-UTFPR. Vinculada ao GEU - Grupo de Estudos sobre Universidade.

3 Doutora em Educação. Docente do PPGDR-UTFPR. Vinculada ao GEU - Grupo de Estudos sobre Universidade.

\begin{tabular}{l|c|c|c}
\hline Rev. Ciências Humanas & Frederico Westphalen, RS & Pg. 109-128 & Maio/Agosto 2019 \\
\hline
\end{tabular}

\begin{tabular}{l|l} 
Recebido em: 22/05/2019 & Aceito em: 04/06/2019
\end{tabular}




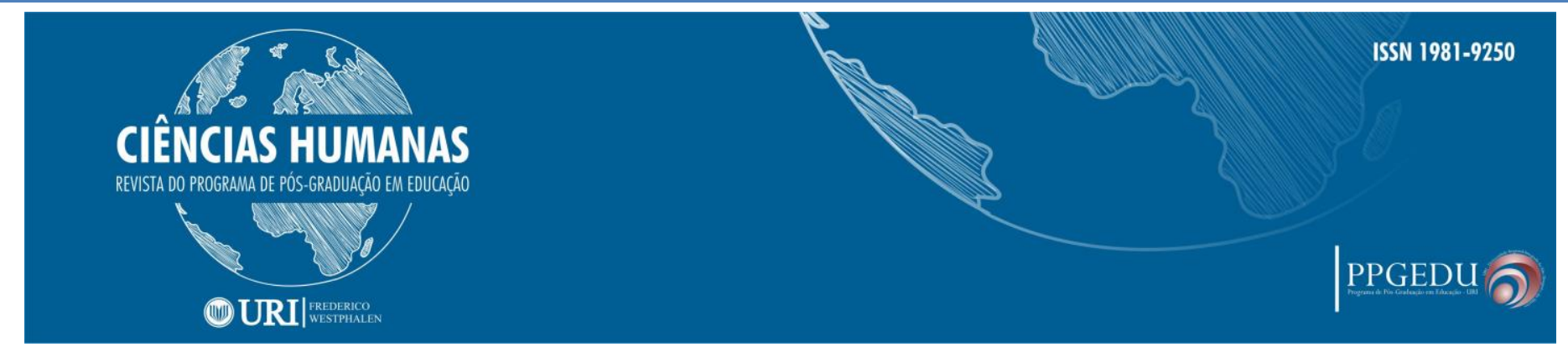

well as to understand its geopolitical aspects. This work consists of a qualitative-descriptive research, on the analysis of documents. The results show that there is a great demand for the areas of knowledge which have a greater emphasis on the application of techniques and technologies directed applied in the job market. Furthermore, since the beginning the PEC-PG has been mainly linked to Latin American countries, motivated by the easiness of access and interchange. However, since the year of 2003 there have been a close approximation between Brazil and Africa through the CSS, due to historical and cultural similarities. Thence, we can observe the intentions and justifications for the internationalization of Undergraduate Education in CSS, by the reinforce of the social, political and economic aspects as well as the Science, Technology and Inovation features. The analyze of the PEC-PG Program shows that it corroborates straightforward with the premises of the internationalization of Undergraduate Education and the intercultural relations when it works together with the reinforce of the countries involved, where Brazil is in the spotlight of a central position of this cooperation.

\section{KEYWORDS}

Undergraduate Education. Internationalization. PEC-PG Program.

\section{RESUMEN}

Analizar los movimientos contemporáneos de la internacionalización de la Educación Superior, presupone comprenderlos como insertados en un telón de fondo complejo e implicados por las relaciones de interculturalidad. En este sentido, este estudio tiene como enfoque la internacionalización de la Educación Superior en el contexto de la Cooperación Sur-Sur (CSS), específicamente, en lo que concierne al Programa de Estudiantes-Convenio de Postgrado (PEC-PG). Para ello, tiene por objetivo caracterizar y discutir elementos preliminares del Programa PEC-PG, así como, comprender aspectos de carácter geopolítico. Se trata de una investigación cualitativa, de tipo descriptivo, de análisis documental. Los resultados demuestran que hay gran demanda por áreas de conocimiento que tienen mayor énfasis en la aplicación de técnicas y tecnologías orientadas al mercado de trabajo. Además, se verifica que el PEC-PG, históricamente, se vinculaba principalmente con países de América Latina, teniendo como principal justificativa la facilidad de acceso e intercambio. Sin embargo, a partir de 2003 hubo una gran aproximación entre Brasil y África, a partir de la CSS, debido a aspectos históricos y culturales muy similares. A partir de eso, se observa la presencia de las ambiciones y justificaciones de la internacionalización de la Educación Superior en la CSS, como fortalecimiento de aspectos sociales, políticos, económicos y de CT \& I. La mirada sobre el Programa PEC-PG evidencia que este corrobora directamente con las premisas de la internacionalización de la Educación Superior y de las relaciones de interculturalidad cuando actúa junto al fortalecimiento de los países involucrados, donde Brasil es un país destacado por protagonizarlo en una posición central de esta cooperación.

PALVARAS CLAVE

Educación Superior. Internacionalización. Programa PEC-PG.

\section{INTRODUÇÃO}

\section{Analisar movimentos contemporâneos vivenciados no contexto da} internacionalização da Educação Superior pressupõe compreendê-los como inseridos num pano de fundo complexo e implicados pelas relações de interculturalidade. É a partir de tal premissa, que o presente artigo tem como intenção contribuir para os diálogos estabelecidos a partir da relação entre cultura, identidade e educação. $O$ estudo tem como enfoque a internacionalização da Educação Superior no contexto da Cooperação Sul-Sul (CSS), mais especificamente, no que concerne ao Programa Estudante-Convênio Pós-Graduação (PEC-

\begin{tabular}{l|l} 
Recebido em: 22/05/2019 & Aceito em: 04/06/2019
\end{tabular}




\section{CIÊNCIAS HUMANAS}

REVISTA DO PROGRAMA DE PÓS-GRADUAĞ̈O EM EDUCAĞ̄o

\section{(1) URI|}

PG). Para tanto, o presente artigo tem como objetivo caracterizar e discutir elementos preliminares do Programa PEC-PG, com o especial intuito de compreender aspectos mais complexos, como por exemplo, as relações de caráter geopolítico.

Entretanto, é salutar evidenciar algumas premissas referentes ao problema de pesquisa, no intuito da compreender a relação dos componentes que o contextualizam, com especial destaque, a Internacionalização da Educação Superior, a Cooperação Sul-Sul, bem como, o objeto de análise em tela, o Programa PEC-PG.

Nesse sentido, para compreender as intencionalidades e dinâmicas assumidas pelo Programa PEC-PG, importa elucidar questões que perpassam processos históricos da internacionalização da Educação Superior e suas intencionalidades, intimamente ligadas ao processo de globalização. Em termos gerais, a globalização caminharia para um mundo onde as fronteiras se tornariam mínimas no que concernem capitais, informações e tecnologias. Diante de tais fluxos globalizados, tenderiam a se destacar atores amparados em grandes corporações transnacionais que não possuiriam raízes com qualquer Estado-Nação. Dessa forma, para ser uma nação, empresa ou indivíduo "bem-sucedido", seria necessária também a maior inserção possível no cenário global e que não estaria desvinculada das formas tradicionais de produção do conhecimento científico (LASTRES e ALBAGLI, 1999). Porém, em muitos espaços, o cenário econômico e social não é favorável para que haja tal interação e fluidez dos fluxos. A globalização de forma simétrica passa a ser uma ideia que nem sempre é posta em prática devido à barreiras criadas pela hegemonia dos países do Norte sobre os países do Sul e que implicam diretamente nas formas pelas quais os processos de internacionalização da Educação Superior encontram alcances, mas também, limites.

Assim, cabe aqui evidenciar que a internacionalização é o relacionamento entre as nações que proporciona trocas e compartilhamentos de suas culturas, sistemas e instituições (KNIGHT, 2012). Nesse sentido, destaca-se que a internacionalização surge então como decorrência do processo de globalização, repercutindo também, em oportunidades para a inserção de nações periféricas neste processo (STALLIVIERI, 2004).

Nesta perspectiva, as intencionalidades da internacionalização da Educação Superior ganharam maior evidência e respaldo a partir da criação do acordo de Cooperação Sul-Sul. A CSS, também conhecida como Cooperação Técnica entre Países em Desenvolvimento 


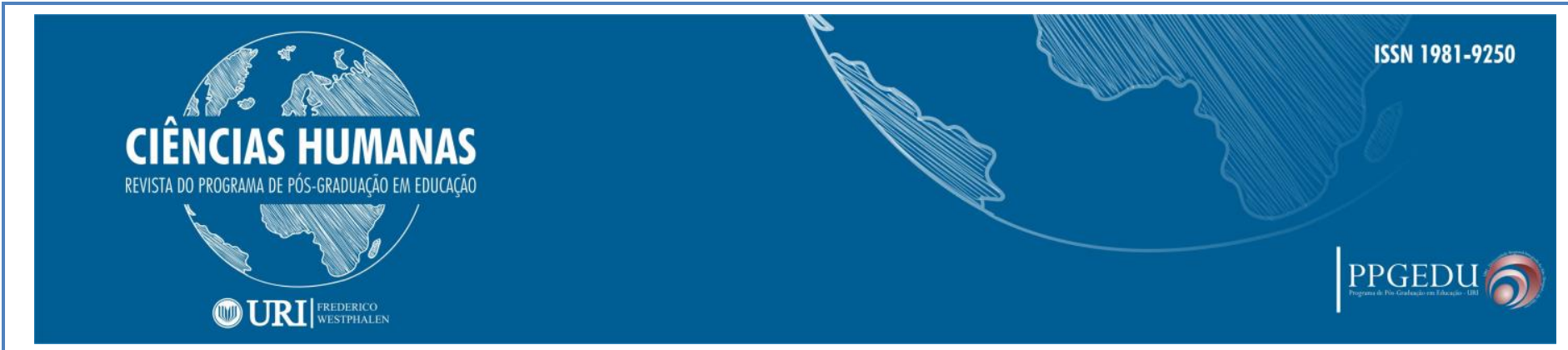

(CTPD), surge como um instrumento a partir de contribuições acerca de produções, tanto técnicas quanto de conhecimento entre os países considerados subdesenvolvidos e em desenvolvimento. Dessa forma, a CSS atribui um importante papel na agenda de políticas externas brasileiras, no sentido de ampliar caminhos para que estes se fortaleçam a partir de trocas de saberes e experiências. Isso significa interagir a partir de locais com dinâmicas que conversam por suas semelhanças, com a finalidade de desenvolver uma menor dependência dos países desenvolvidos, especialmente, por meio de pesquisas que promovam o desenvolvimento. Dentre estas trocas, a internacionalização da Educação Superior ganha espaço privilegiado por meio de alguns programas específicos institucionalizados através de políticas públicas com tal fim.

Diante de tal cenário, verifica-se a origem do Programa PEC-PG, criado em 1981, cujas atividades iniciaram no ano de 1983. O programa objetivou promover o intercâmbio de estudantes advindos de países em desenvolvimento para realizar a Pós-Graduação em universidades brasileiras. Possui como base de apoio a Coordenação de Aperfeiçoamento de Pessoal de Nível Superior (CAPES), o Ministério das Relações Exteriores (MRE) e o Conselho Nacional de Pesquisa $(\mathrm{CNPq})$, responsáveis pelo pagamento de bolsas de mestrado e doutorado, divulgação do Programa no exterior e auxílio financeiro para retorno dos estudantes aos países de origem.

Nesse sentido, o PEC-PG dialoga com a internacionalização da Educação Superior, tendo em vista as intenções acerca das influências socioeconômicas locais e globais. Da mesma maneira, é importante considerar sua forte contribuição na construção de conhecimentos em Ciência, Tecnologia e Inovação, de maneira mais específica e incisiva, auxiliando no atendimento das características do desenvolvimento de pesquisa na PósGraduação. Logo, a análise preliminar do Programa PEC-PG faz-se valiosa no auxílio de análises posteriores, na perspectiva de que a cooperação entre países com características sociais e econômicas semelhantes pode possibilitar diálogos construtivos acerca de dinâmicas que regem a sociedade e a economia, permitindo avaliar alcances e limites.

Em termos metodológicos, o estudo possui como abordagem a natureza qualitativa, de caráter descritivo. Para tanto, trata-se de pesquisa documental, que buscou apropriar-se especialmente dos documentos orientadores do Programa PEC-PG, dos seus relatórios de 


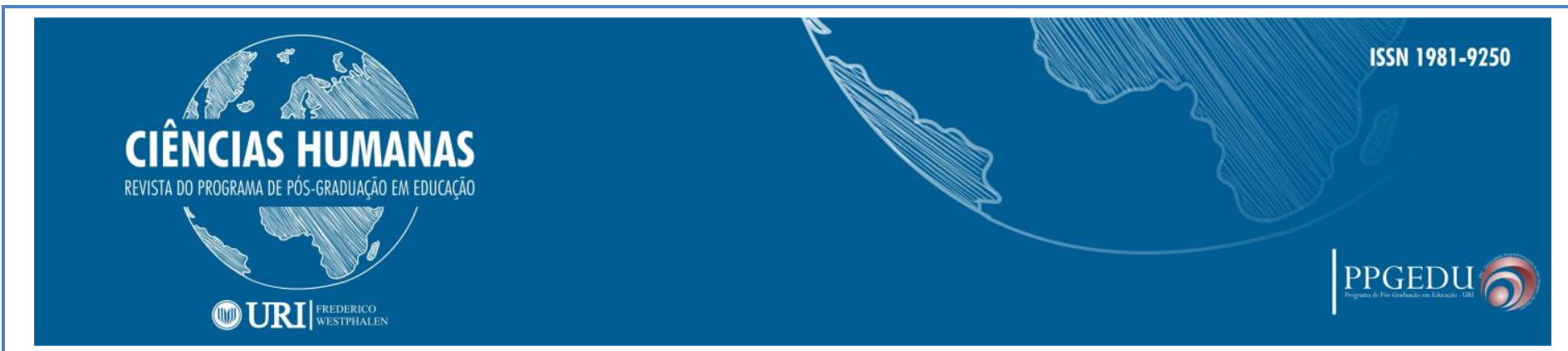

gestão e de informações disponíveis nos sites e documentos institucionais que o conduzem.

No que tange a estrutura de apresentação deste artigo, a mesma encontra-se organizada da seguinte forma: em um primeiro momento é realizada uma revisão de literatura referente às principais ancoragens teóricas que sustentam a discussão, seguido de um segundo momento, que se propõe a discutir a internacionalização da Educação Superior como forma de contextualizar o Programa PEC-PG. O terceiro momento, por sua vez, dedica-se a realizar uma abordagem histórica do Programa, bem como, a interpretação de dados referentes ao PEC-PG. Por fim são apresentadas as principais sínteses acerca do estudo.

\section{INTERNACIONALIZAÇÃO DA EDUCAÇÃO SUPERIOR: PARA COMPREENDER O PROGRAMA DE ESTUDANTES-CONVENIO DE PÓS-GRADUAÇÃO (PEC-PG)}

Antes mesmo de uma caracterização da internacionalização do Ensino Superior propriamente dita, é necessário conceituar a perspectiva de internacionalização assumida na presente discussão. Para Knight (2005), a definição de internacionalização pode ser percebida a partir de concepções divergentes, conforme a coordenada e ponto de vista em que se encontra o indivíduo. Logo, é imprescindível compreender que a globalização e a internacionalização não são sinônimas, e sim dois conceitos diferentes que estão intimamente ligados e correlacionados. Nesse sentido, Knight (2012) caracteriza a globalização como um fluxo mundial, de culturas, economias, informações, tecnologias e outros, com unanimidade de trânsito nos meios em que estes são produzidos e reproduzidos. A internacionalização, por sua vez, é o relacionamento entre as nações que proporciona trocas e compartilhamentos de suas culturas, sistemas e instituições.

Para Wit (2013), a internacionalização da Educação Superior é um conceito relativamente jovem, tributário do termo denominado "educação internacional". Para o autor, tal perspectiva assume importância tendo em vista a abrangência das atividades universitárias, fragmentadas e enquadradas nas limitações da internacionalização, por decorrência de alguns fatores políticos como a quebra da cortina de ferro, a unificação da Europa e o impulso da globalização decorrente das mudanças políticas e sociais mundiais. A partir daí, houve uma transferência do termo "educação internacional" para o conceito de internacionalização da 


\section{CIÊNCIAS HUMANAS}

REVISTA DO PROGRAMA DE PÓS-GRADUAĞ̈O EM EDUCAĞ̄o

\section{(1) URI|}

Educação Superior. Nessa perspectiva, o conceito orientador do presente estudo, em termos de internacionalização da Educação Superior, se filia à perspectiva de que a internacionalização da Educação Superior é "o processo que integra uma dimensão global, intercultural e internacional nos objetivos, funções e oferta da educação pós-secundária" (MOROSINI apud KNIGHT, 2017. p. 11).

Durante muito tempo a internacionalização foi vista como pertencente somente aos países desenvolvidos do Norte, repercutindo aos países subdesenvolvidos do Sul um papel de inferioridade numa atmosfera envolta num caráter neocolonial. Após o processo de globalização atingir as nações das mais variadas condições socioeconômicas, principalmente após a emergência de alguns países do Sul, uma mudança notável vem ocorrendo nos contornos da internacionalização da Educação Superior (WIT, 2013). Essa mudança implicou tanto na sua conceitualização quanto nos cenários onde ela atua.

Partindo deste pressuposto, nota-se uma forte relação da internacionalização da Educação Superior com o Estado, que é justificada devido ao fato de que a internacionalização possui caráter de relacionamento entre nações. Isso por que é a partir do Estado que são apontadas as demandas necessárias para o que é identificado como desenvolvimento. Soma-se a este fato, a posição da Universidade como produtora de conhecimento e sua importância estratégica nos processos de desenvolvimento. Há que se considerar o entrelaçamento da educação com a globalização, tendo em vista a conjuntura na qual o conhecimento foi alçado a um dos principais valores do processo globalizante e do modo de produção vigente. Ademais, o Estado se encontra numa posição de mediador da internacionalização, pela responsabilidade perante os movimentos idealizadores de estratégias e ações no âmbito de seus territórios. Nesse sentido, a internacionalização da Educação Superior torna-se uma via para atender as demandas dos territórios a caminho do desenvolvimento, da forma a ser caracterizada como um conceito complexo que adquiriu uma grande diversidade de termos e reflexões (MOROSINI, 2017). Soma-se a este fato, a posição da Universidade como produtora de conhecimento científico, instituição necessária ao processo de desenvolvimento sustentável e local. Ainda, o diálogo entre Estado e conhecimento pode ser percebido a partir da complexidade assumida entre o campo profissional e o campo científico. 


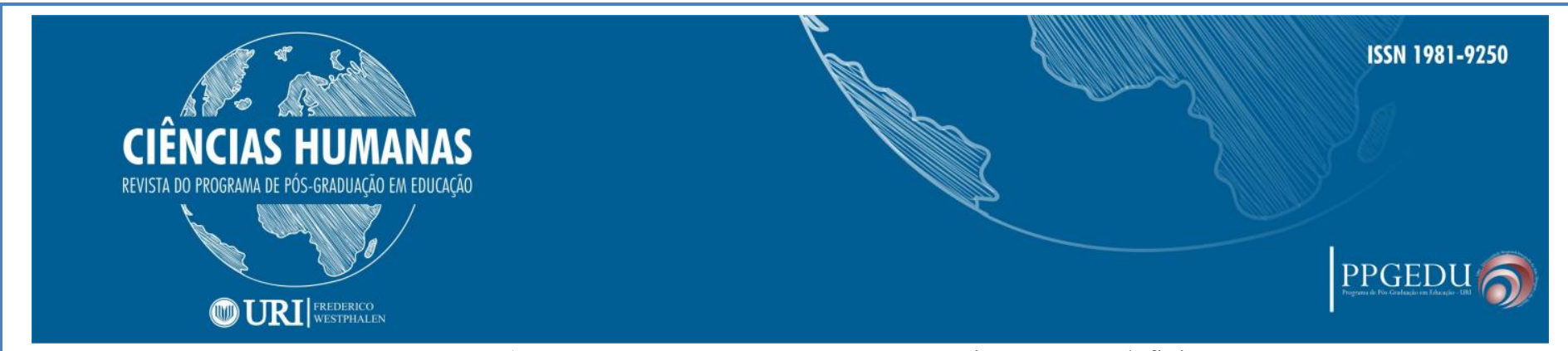

A separação entre os campos, que anteriormente se definia por atuações quase que distintas, hoje, com esta característica de Estado, assume uma preponderância da influência do campo profissional na configuração do científico. Ou seja, as determinações do mercado de trabalho sobre a universidade vêm transformando os princípios das mesmas, como apontado em inúmeros trabalhos, não só internacionais, mas nacionais (MOROSINI apud SGUISSARDI eSILVA JUNIOR, 2006, p. 05).

Entretanto, há ainda outras distinções importantes no cenário em análise. Considerando que a educação é vista como um bem público, difere-se do ensino, visto como uma ferramenta que impulsiona o desenvolver de uma economia e uma sociedade global. .A pesquisa, por sua vez, realizada pela Universidade pressupõe a autonomia do pesquisador, e maior aderência à internacionalização, enquanto que o ensino é controlado pelo Estado dificultando a autonomia e regulação nos mesmos contextos da internacionalização. Assim, os desafios, possibilidades e articulações da internacionalização da Educação Superior merecem algumas considerações para uma melhor compreensão de como esta influencia e sofre influências das dimensões globais e locais. Dessa forma, as universidades caminham para uma maior visibilidade e competência na resposta de exigências locais, assim como do contexto geopolítico global e do processo de integração (FEIJÓ, 2013).

Com fundamento nessas pontuações, considera-se que para auxiliar uma aproximação e relação entre os países periféricos, alguns acordos e parcerias foram criados, como, por exemplo, o Acordo de Cooperação Sul-Sul. A CSS surge como um instrumento que visa o desenvolvimento a partir de contribuições acerca de produções, técnicas e conhecimento entre os países do Sul. Nesse sentido, Chediek (2017) lembra que se trata de um complemento e não uma substituição das relações Norte-Sul, não excluindo a importância dessa relação centro-periferia.

A iniciativa de criar acordos internacionais, especialmente entre os países do Sul foi tratada com intensidade pela Agência Brasileira de Cooperação (ABC). Criada em setembro de 1987, a partir da integração da estrutura do MRE, a ABC possui como competência planejar, coordenar, negociar, aprovar, executar, acompanhar e avaliar, em âmbito nacional, programas, projetos e atividades de cooperação para o desenvolvimento em todas as áreas do conhecimento, recebida de outros países e organismos internacionais e aquela entre o Brasil e países em desenvolvimento, incluindo ações relacionadas ao campo de capacitação para a gestão da cooperação técnica e disseminação de informações (MRE, 2017). Logo, suas \begin{tabular}{l|c|c|l} 
Rev. Ciências Humanas & Frederico Westphalen, RS & Pg. 109-128 & Maio/Agosto 2019 \\
\hline
\end{tabular} 


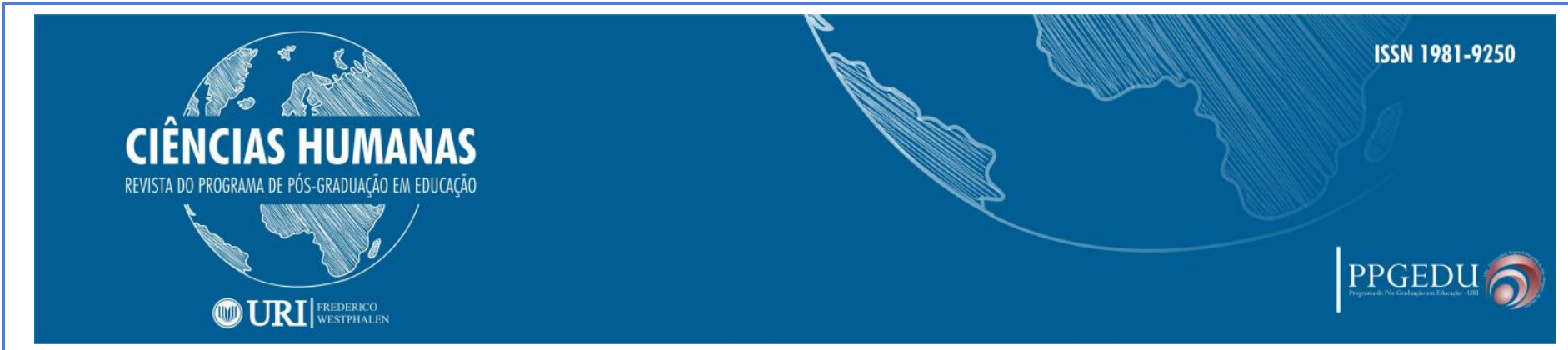

competências se referem aos Acordos de Cooperação Sul-Sul. Inseridos nos Acordos de Cooperação Internacionais e coordenados pela $\mathrm{ABC}$, é possível destacar como programas direcionados à Internacionalização da Educação Superior, a Cooperação Técnica Internacional (CTI). Nesse sentido, a CTI surge como um meio de construir um cenário propício de mudanças socioeconômicas dos países envolvidos, a partir do desenvolvimento de capacidades relacionadas à conhecimentos e tecnologias aplicadas no âmbito do desenvolvimento alinhados a objetivos comuns (MRE, 2017).

No bojo da CTI, encontra-se a Cooperação Técnica Sul-Sul, que dialoga com o compartilhamento de práticas disponíveis entre os países do Sul a fim do fortalecimento das relações dinâmicas cooperantes entre países com quadros semelhantes de desenvolvimento, acompanhando e avaliando os resultados, possuindo assim um caráter de cooperação mútua (MRE, 2014, s.p.).

Dessa forma, a CSS aparece como um mecanismo de fortalecimento institucional de todos os envolvidos, especialmente de países periféricos, cujo intuito visava a transferência e absorção de conhecimento de forma efetiva.. Dentre as áreas que a CSS se concentra, a educação encontra-se como uma área muito importante para a relação de cooperação técnica, essencial para o desenvolvimento. Os projetos existentes nestes acordos, principalmente os relacionados à internacionalização da Educação Superior possuem maior representatividade nas relações entre os países da América Latina e da África (em especial os Países Africanos de Língua Oficial Portuguesa - PALOP). Ainda, alguns programas direcionados à internacionalização da Educação Superior ganham destaque, representados por Programas para Estudantes-Convênio Graduação (PEC-G) e Pós-Graduação (PEC-PG); o Programa Celpe-Bras; o Programa Ciência sem Fronteiras (CsF); o Programa Idiomas sem Fronteiras (IsF); a Promoção da Educação Superior no Mercado Comum do Sul (MERCOSUL), por exemplo (ABC, 2014).

Nesta perspectiva, a CSS surge como uma medida governamental que possibilita a emergência deste conhecimento único, que surge a partir das dinâmicas do Sul. Neste sentido, o Programa PEC-PG, objeto deste estudo, surge como um programa estratégico de internacionalização da Educação Superior que se encontra no bojo das ações da CSS. Buscase aqui reunir elementos que se dediquem a compreender os tensionamentos a partir da produção do conhecimento e aplicação para o desenvolvimento dos países envolvidos. 


\section{PROCEDIMENTO METODOLÓGICO}

Tendo em vista a problemática do presente estudo, torna-se imprescindível a realização de uma caracterização preliminar, como forma de compreender questionamentos e tensionamentos que permeiam o tema desta pesquisa. Nesse sentido, denota-se o caráter descritivo do referido estudo, com a finalidade de obter maiores informações sobre a temática, possibilitando a formulação de hipóteses e buscando um conhecimento com maior profundidade (GIL, 1999). Além disso, no sentido de estabelecer uma abordagem adequada frente ao objeto de estudo pretendido, especifica-se o Programa PEC-PG no âmbito das relações de cooperação Sul-Sul, considerando a perspectiva da pesquisa descritiva como sendo a mais oportuna em termos de abordagem. Como anuncia Gil (1999), objetiva-se descrever características das relações entre as variáveis de um estudo.

Como dito anteriormente, o objeto de estudo refere-se ao Programa EstudanteConvênio Pós-Graduação. Assim, a pesquisa documental foi predominante na condução do estudo, principalmente a partir de documentos emanados pelo Estado brasileiro, com especial destaque relativo aos órgãos que o efetivam. Dentre eles destaca-se a ABC - Agência Brasileira de Cooperação, o MRE-Ministério das Relações Exteriores, o CNPq-Conselho Nacional de Desenvolvimento Científico e Tecnológico e a CAPESCoordenação de Aperfeiçoamento de Pessoal de Nível Superior, como principais fontes de documentos. Entre estes documentos encontram-se manuais de gestão, tanto da CSS quanto do PEC-PG, leis federais referentes a planos de desenvolvimento e educação, bem como, da internacionalização da Educação Superior, sites que elucidam processos e resultados referentes ao objeto de estudo, contendo dados quantitativos e qualitativos do intercâmbio de estudantes inclusos no PEC-PG.

A partir da obtenção dos dados, é importante realizar uma categorização para a análise dos mesmos, a fim de proporcionar uma linha de sistematização, facilitando a tarefa e evitando erros de repetição ou exclusão de dados. As categorias podem surgir antes da obtenção dos dados, durante ou depois. Dessa forma, é possível uma aproximação com os detalhes dos dados, bem como determinar perspectiva de relações entre as categorias (BOGDAN; BIKLEN, 1994). 


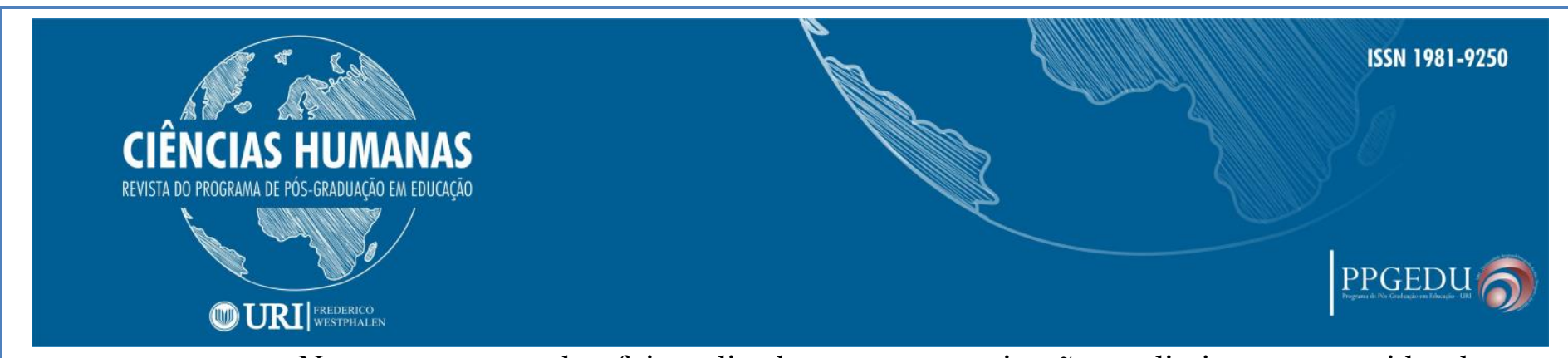

No presente estudo, foi realizada uma categorização preliminar no sentido de especificar: número de estudantes participantes, países envolvidos, bem como, instituições vinculadas ao PEC-PG tanto no que tange universidades públicas e privadas. A caracterização preliminar permitirá aprofundar futuramente a perspectiva geopolítica na análise dos dados, evidenciando imbricações do Programa PEC-PG nas estratégias, ações e tensionamentos entre os países envolvidos.

\section{O PROGRAMA DE ESTUDANTES-CONVÊNIO DE PÓS-GRADUAÇÃO (PEC-PG): CARACTERIZAÇÕES INICIAIS}

Apesar da inconsistência de programas específicos que tratassem da internacionalização da Graduação e da Pós-Graduação em outros momentos históricos, a atratividade de estudantes estrangeiros para o Brasil não é uma ocorrência tão recente. Porém, devido às questões hegemônicas e as oportunidades privilegiadas ofertadas a estudantes dos países dominantes, a ocorrência desta internacionalização se restringia à vinda de estudantes provenientes de uma situação favorável, como estudantes de famílias e países de elite interessados em questões particulares do país. Apesar de o Programa PEC-PG proporcionar com maior facilidade esta oportunidade preferencialmente a estudantes de países emergentes, ele foi criado com o intuito de regulamentar o acesso dos estrangeiros no Brasil de forma mais ampla (AMARAL, 2013).

Exemplo disso é o PEC-G - Programa de Estudantes-Convênio de Graduação. O programa surge em 1965, num contexto de intenso fluxo migratório de estudantes tornando necessária uma regulamentação desta atividade, para unificar as condições de intercâmbio estudantil (MRE, 2018). Este é um programa criado pelo governo com o caráter de cooperação entre países em desenvolvimento, abrangendo estudantes advindos, especialmente, das Américas, da África e da Ásia.

Devido à visibilidade da importância da Pós-Graduação no contexto de desenvolvimento e da internacionalização, explicitada nos Planos Nacionais da PósGraduação (PNPG), surge então como uma forma de extensão do programa e especificação da Pós-Graduação o Programa de Estudantes-Convênio de Pós-Graduação. O mesmo foi criado em 1981, mas iniciou suas atividades em 1983, através de uma parceria entre a CAPES,

\begin{tabular}{c|c|c|c}
\hline Rev. Ciências Humanas & Frederico Westphalen, RS & Pg. 109-128 & Maio/Agosto 2019 \\
\hline \multicolumn{2}{c}{ Recebido em: 22/05/2019 } & Aceito em: 04/06/2019
\end{tabular}




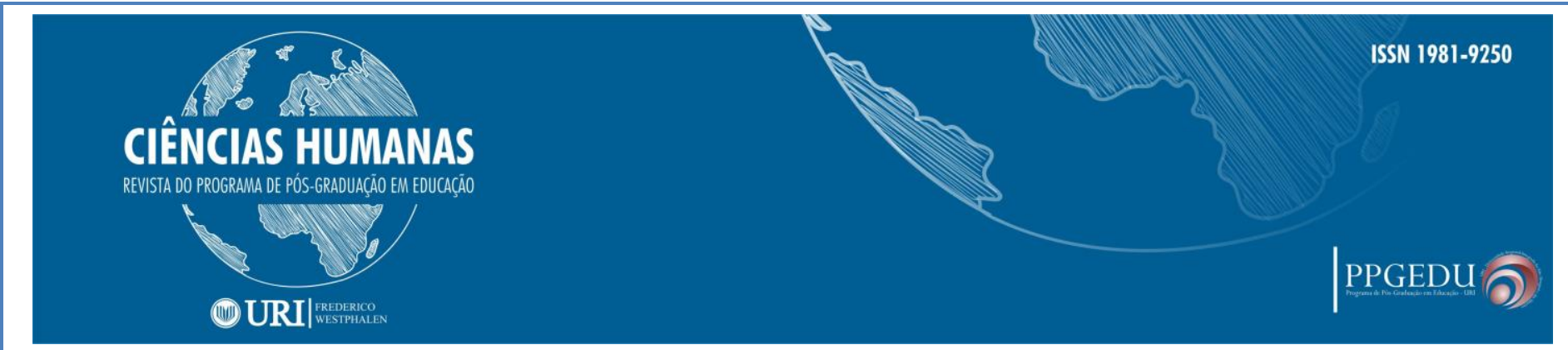

responsável pela seleção e pagamento de bolsas de doutorado para estudantes advindos dos países participantes do programa e bolsa de mestrado para estudantes do Timor-Leste. O MRE responsabilizou-se pela divulgação do Programa no exterior e pagamento das passagens de retorno ao país de origem dos estudantes. Ainda, destaca-se a parceria com o CNPq, responsável pelo pagamento de bolsas de mestrado para estudantes de todos os países participantes, com exceção de Timor Leste (CAPES, 2017).

O Programa oferta a realização de cursos de Pós-Graduação realizados no Brasil para estudantes oriundos de países em desenvolvimento, buscando alcançar contribuições necessárias pra o desenvolvimento do país. Da mesma maneira visa ofertar trocas de informações que possibilitam o desenvolvimento do Brasil através da formação de recursos humanos com países com os quais o Brasil mantém Acordo de Cooperação Educacional, Cultural ou de Ciência e Tecnologia. Em termos de abrangência, o programa integra a América-Latina e Caribe (25 países), a África (24 países) e Ásia (7 países) com universidades públicas e privadas conforme mostra o quadro 1 e o quadro 2, se enquadrando, portanto, como um programa aderente à Cooperação Sul-Sul (MRE, 2018).

Quadro 1: Universidades públicas brasileiras parceiras do PEC-PG por região

\begin{tabular}{|c|c|c|c|c|}
\hline \multicolumn{5}{|c|}{$\begin{array}{l}\text { UNIVERSIDADES PÚBLICAS BRASILEIRAS PARCEIRAS DO PEC-PG POR } \\
\text { REGIÃO }\end{array}$} \\
\hline Região Sudeste & $\begin{array}{l}\text { Região } \\
\text { Nordeste }\end{array}$ & $\begin{array}{l}\text { Região } \\
\text { Sul }\end{array}$ & $\begin{array}{l}\text { Região } \\
\text { Norte }\end{array}$ & $\begin{array}{l}\text { Região Centro- } \\
\text { Oeste }\end{array}$ \\
\hline IFTM & INPE & FURG & INPA & UFG \\
\hline IMPA & UEFS & UDESC & UFAM & UFMS \\
\hline Instituto de Botânica/SP & UFAL & UEL & UFPA & UFMT \\
\hline FRIOCRUZ/MG & UFBA & UEM & UFRA & UnB \\
\hline FIOCRUZ/RJ & UFC & UEPG & & \\
\hline UENF & UFCG & UFFS & & \\
\hline UERJ & UFPB & UFPel & & \\
\hline UFABC & UFPE & UFPR & & \\
\hline UFF & UFRB & UFRGS & & \\
\hline UFJF & UFRN & UFSC & & \\
\hline UFMG & UFRPE & UFSM & & \\
\hline UFLA & FUFSE & UTFPR & & \\
\hline \multicolumn{5}{|l|}{ UFRJ } \\
\hline \multicolumn{5}{|l|}{ UFRRJ } \\
\hline Rev. Ciências Humanas & Frederico We & RS & Pg. 109-128 & Maio/Agosto 2019 \\
\hline \multicolumn{2}{|c|}{$\begin{array}{l}\text { Recebido em: 22/05/2019 } \\
\end{array}$} & \multicolumn{3}{|c|}{ Aceito em: 04/06/2019 } \\
\hline
\end{tabular}




\section{(1) URI|}

UFSCar

UFTM

UFU

\begin{tabular}{lcccc}
\hline \multicolumn{1}{c}{ Região Sudeste } & $\begin{array}{c}\text { Região } \\
\text { Nordeste }\end{array}$ & $\begin{array}{c}\text { Região } \\
\text { Sul }\end{array}$ & $\begin{array}{c}\text { Região } \\
\text { Norte }\end{array}$ & $\begin{array}{c}\text { Região Centro- } \\
\text { Oeste }\end{array}$ \\
\hline UFV & & & & \\
UNESP & & & \\
UNICAMP & & \\
UNIFEI & & \\
UNIFESP & & \\
UNIRIO & & \\
USP & & & \\
\hline
\end{tabular}

Fonte: MEC, 2018.

Assim como o Programa pressupõe a participação das instituições públicas, é importante destacar o papel das instituições privadas nesse cenário, com participação em todas as regiões do país e que dialogam com movimentos nacionais de expansão da educação superior, não apenas no contexto da Graduação, mas também, da Pós-Graduação.

Quadro 2: Universidades privadas brasileiras parceiras do PEC-PG por região

\section{UNIVERSIDADES PRIVADAS BRASILEIRAS PARCEIRAS DO PEC-PG POR REGIÃO}

\begin{tabular}{llll}
\hline Região Sudeste & Região Sul & Região Centro-Oeste & Todas as Regiões \\
\hline FGV/RJ & FURB & UCB & SENAC \\
PUC/Rio & PUC/RS & & \\
PUC/SP & PUC/PR & & \\
PUC/MG & UNESC & & \\
UMC & UNISINOS & \\
UNIBAN & UNIVALI & \\
\hline
\end{tabular}

Fonte: MEC, 2018.

\begin{tabular}{l|l|l|l}
\hline Rev. Ciências Humanas & Frederico Westphalen, RS & Pg. 109-128 & Maio/Agosto 2019 \\
\hline
\end{tabular}




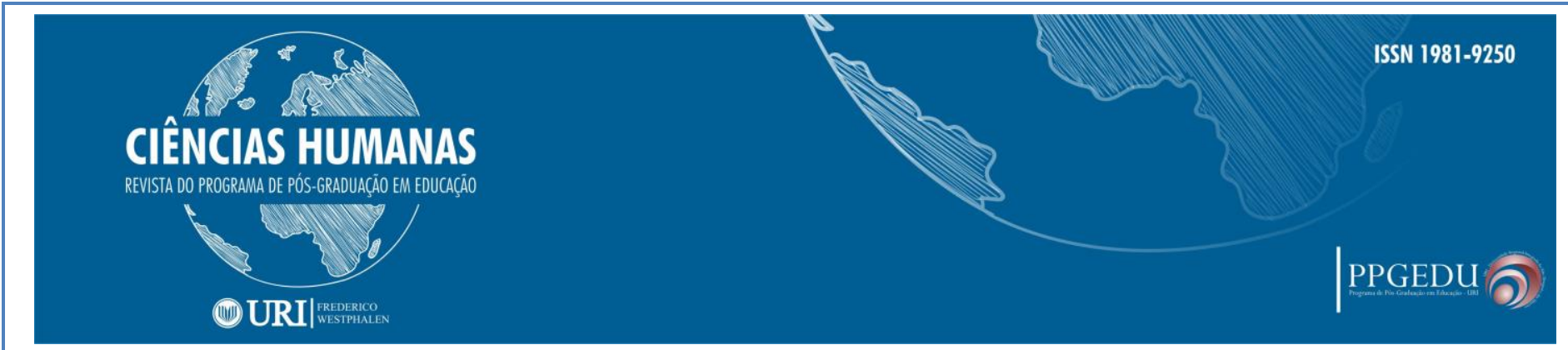

Em se tratando de aspectos atinentes à participação dos estudantes no Programa, alguns requisitos exigidos são especificados pela CAPES e que reforçam as intencionalidades dos processos de cooperação com países em desenvolvimento, estabelecendo um alinhamento importante com a Cooperação Sul-Sul. Dentre tais aspectos, destacam-se os seguintes critérios:

a) Ser cidadão de país em desenvolvimento com o qual o Brasil mantenha Acordo ou Memorando de Entendimento na área de Cooperação Cultural, Educacional ou de Ciência e Tecnologia.

b) Não ser cidadão brasileiro, ainda que binacional, nem possuir genitor ou genitora brasileiro;

c) Não possuir visto permanente, visto diplomático, visto Mercado Comum do Sul (MERCOSUL) ou visto que autorize o exercício de atividade remunerada no Brasil;

d) Ter curso de graduação ou mestrado completo em uma das áreas do conhecimento científico;

e) Ser aceito por Instituição de Ensino Superior brasileira (IES), pública ou privada, em curso de mestrado ou doutorado avaliado pela CAPES com conceito igual ou superior a 03 (três).

f) Ter Curriculum Vitae cadastrado e/ou atualizado na Plataforma Lattes do CNPq, em Língua Portuguesa.

g) Ser financeiramente responsável pela passagem de vinda para o Brasil, por sua manutenção até o recebimento da primeira mensalidade da bolsa PEC-PG e pela manutenção de qualquer membro da família que o acompanhe durante toda a estada no Brasil;

h) Ser portador do Certificado de Proficiência em Língua Portuguesa (CELPE-Bras), inclusive para oriundos de países lusófonos.

i) Ter permanecido em seu país por, pelo menos, dois anos após ter obtido o diploma brasileiro, no caso de ex-estudante graduado pelo Programa de Estudantes-Convênio de Graduação - PEC-G (CAPES, 2017). 


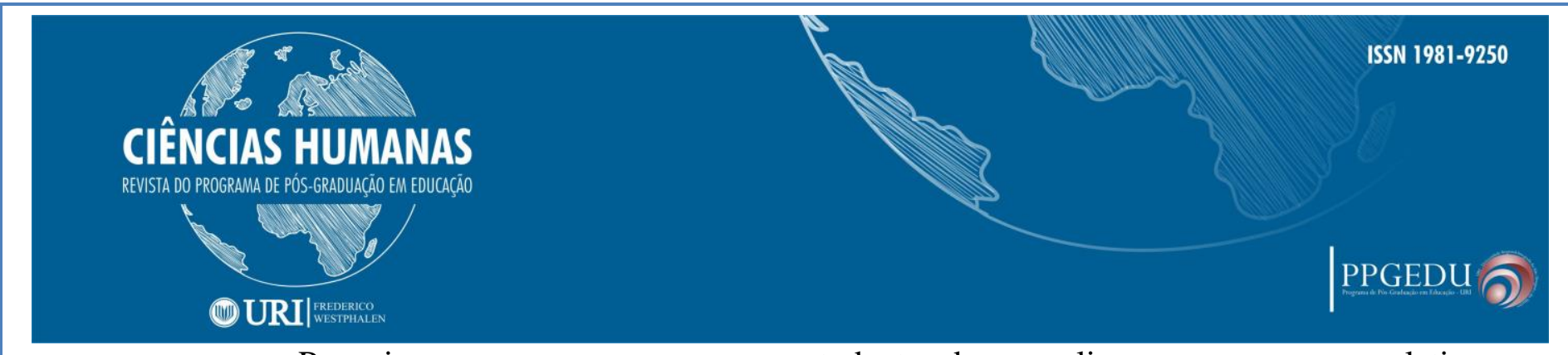

Para ingressar no programa o estudante deve realizar um processo seletivo constituído por três etapas. Na primeira etapa, as agências financiadoras consideram as especificidades exigidas e realizam a pré-seleção das candidaturas. $\mathrm{Na}$ segunda etapa, os candidatos pré-selecionados são encaminhados para julgamento do mérito técnico-científico. Estas candidaturas recomendadas por mérito técnico-científico são submetidas à seleção final pelas agências financiadoras para priorização sendo ratificadas pelo Grupo de Supervisão do PEC-PG em reunião específica. A divulgação dos candidatos selecionados acontece nas páginas eletrônicas do CNPq, da Capes e da DCE (MRE, 2018).

Após ingressar no programa, devem ser tomadas algumas providências pelo estudante, tais como confirmar dentro do prazo estabelecido, a Capes ou ao CNPq a aceitação ou não da bolsa. Caso haja o aceite, deve ser solicitado Visto Temporário junto à missão diplomática brasileira em seu país. É também de responsabilidade do estudante observar o calendário acadêmico da universidade de destino e se apresentar na data correta para a matrícula e iniciar os estudos do ano letivo (MRE, 2018).

A partir do momento em que o estudante é aprovado e aceito pelo Programa de PósGraduação, o mesmo receberá benefícios coordenados pelo MRE, especialmente no que tange a gastos com assistência médica, farmacêutica e odontológica, mediante atendimento do Sistema Único de Saúde - SUS (LIBERATO, 2012). Além disso, os seguintes benefícios são ofertados:

a) Vagas em IES brasileiras recomendadas pela Capes, sem custos de matrícula;

b) Bolsa mensal no mesmo valor que a oferecida aos estudantes brasileiros, a saber: $\mathrm{R} \$ 1500,00$ para mestrado, com duração máxima de 24 meses, e $\mathrm{R} \$ 2200,00$ para doutorado, com duração máxima de 48 meses; e

c) Passagem aérea de retorno ao país do estudante estrangeiro (MRE, 2018).

Além disso, dentre os objetivos de uma cooperação ente países em desenvolvimento que envolve a internacionalização da Educação Superior está a busca por intercâmbios internacionais de saberes e experiências que impulsionem o desenvolvimento regional. Tornase importante então averiguar quais as áreas de conhecimento que ganharam maior destaque no âmbito do Programa. Segundo dados do Instituto de Pesquisa Econômica Aplicada-IPEA (2016), entre os anos de 2011 e 2013, através do PEC-PG houve um destaque no ingresso de 


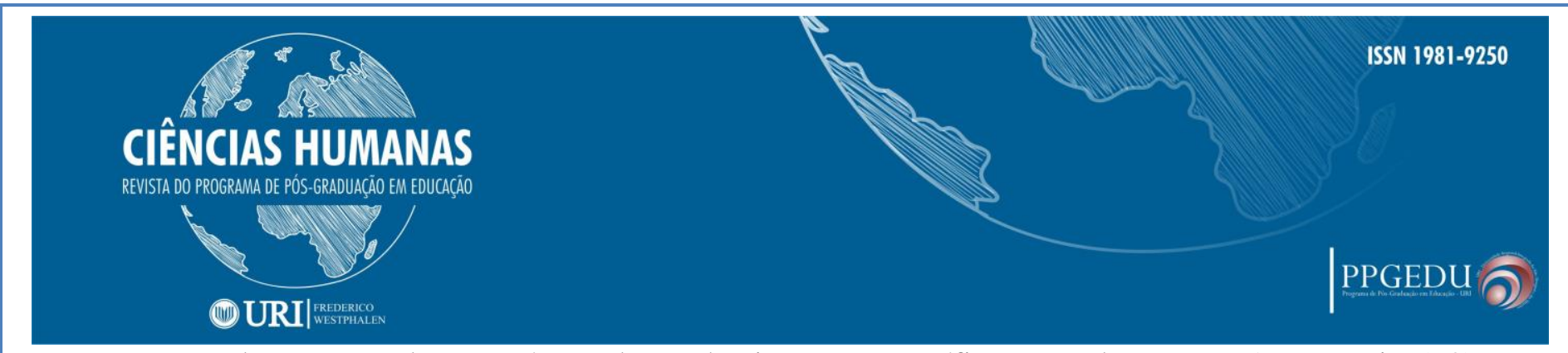

estudantes em algumas áreas de conhecimento específicas, a saber.: s : Agronomia (70), Medicina Veterinária (46), Zootecnia (39), Ciência Política (32), Educação (34), Antropologia (31), Sociologia (27), Recursos Florestais e Engenharia Florestal (23), Economia (22), Psicologia (21) e Zoologia (20).

Percebe-se uma grande procura por áreas de conhecimento específicas que possuem maior ênfase na aplicação de técnicas e tecnologias voltadas ao mercado de trabalho. Porém, a procura por áreas de conhecimento que dão maior ênfase a questões socioeconômicas é mais variada e menos concentrada, ou seja, há uma maior variedade de áreas de conhecimento, mas menor concentração de ingressos em cada uma delas.

Além disso, é importante evidenciar que o PEC-PG possuía historicamente vinculações mais consistentes com países da América Latina, tendo como principal justificativa facilidade de acesso e intercâmbio e pelo menor reconhecimento da CSS. Contudo, a partir do governo Lula (2003 - 2011), houve uma grande aproximação do Brasil e da África, a partir da CSS. Isso se deve por decorrência de aspectos históricos e culturais dialógicos com o Brasil. A partir disso, pode-se observar a presença das ambições e justificativas da internacionalização da Educação Superior na CSS, como fortalecedor de aspectos sociais, políticos, econômicos e de CT\&I advindo da cooperação entre países em desenvolvimento e de condições semelhantes afim de um fortalecimento interno a partir de um olhar singular. Dentre estes aspectos históricos e culturais podemos citar o passado comum inserido em um contexto de colônia de exploração, a língua portuguesa e a forte presença da cultura africana no Brasil (LIBERATO, 2012). Dentre as medidas tomadas, encontram-se a criação da Universidade Federal da Integração Internacional da Lusofonia Afro-Brasileira (UNILAB), que abriu as portas para a maior participação dos países africanos, em especial os Países Africanos de Língua Oficial Portuguesa (PALOP), tendo em vista a ambição por divulgar e valorizar a cultura e idioma (MILANI, 2016). Observando a tabela 1, pode-se chegar a algumas reflexões referentes aos movimentos migratórios de cada um dos três continentes a partir do PEC-PG. 


\section{CIÊNCIAS HUMANAS}

REVISTA DO PROGRAMA DE PÓS-GRADUAÇ̄OA EM EDUCAÇ̄OO

(1) URI/

PPGEDU ๑

Tabela 1: Distribuição de selecionados por país 2005 - 2016

\begin{tabular}{|c|c|c|c|c|c|c|c|c|c|c|c|c|c|c|}
\hline \multicolumn{15}{|c|}{ PEC-PG distribuição de selecionados por país 2005 - 2016} \\
\hline PAÍS/ANO & 2005 & 2006 & 2007 & 2008 & 2009 & 2010 & 2011 & 2012 & 2013 & 2014 & 2015 & $2016^{*}$ & Total por país & $\%$ \\
\hline Angola & 2 & 3 & 7 & 5 & 2 & 8 & 10 & 8 & 2 & 3 & 8 & 4 & 62 & $3 \%$ \\
\hline Argentina & 10 & 11 & 16 & 8 & 16 & 14 & 6 & 5 & 4 & 4 & 3 & 5 & 102 & $4 \%$ \\
\hline Benin & 0 & 0 & 0 & 0 & 1 & 0 & 1 & 2 & 1 & 0 & 1 & 3 & 9 & $0 \%$ \\
\hline Bolívia & 5 & 6 & 10 & 7 & 13 & 8 & 8 & 4 & 7 & 6 & 4 & 4 & 82 & $4 \%$ \\
\hline Cabo Verde & 12 & 22 & 6 & 8 & 7 & 15 & 4 & 14 & 13 & 14 & 7 & 10 & 132 & $6 \%$ \\
\hline Camarões & 0 & 0 & 0 & 2 & 0 & 0 & 0 & 1 & 0 & 0 & 1 & 0 & 4 & $0 \%$ \\
\hline Chile & 2 & 8 & 6 & 7 & 6 & 5 & 5 & 11 & 5 & 5 & 12 & 2 & 74 & $3 \%$ \\
\hline China & 1 & 1 & 0 & 0 & 0 & 0 & 1 & 3 & 2 & 1 & 1 & 1 & 11 & $0 \%$ \\
\hline Colômbia & 11 & 43 & 26 & 51 & 79 & 61 & 68 & 66 & 0 & 75 & 43 & 11 & 644 & $28 \%$ \\
\hline Costa do Marfim & 3 & 1 & 3 & 0 & 0 & 0 & 0 & 1 & 1 & 0 & 1 & 0 & 10 & 0\% \\
\hline Costa Rica & 3 & 4 & 1 & 1 & 4 & 2 & 3 & 1 & 4 & 2 & 0 & 0 & 25 & $1 \%$ \\
\hline Cuba & 4 & 1 & 4 & 5 & 5 & 4 & 6 & 5 & 14 & 21 & 28 & 8 & 105 & $5 \%$ \\
\hline Egito & 0 & 0 & 0 & 1 & 0 & 0 & 0 & 0 & 0 & 0 & 0 & 1 & 2 & 0\% \\
\hline El Salvador & 0 & 0 & 0 & 2 & 0 & 1 & 0 & 0 & 0 & 0 & 1 & 0 & 4 & $0 \%$ \\
\hline Equador & 6 & 5 & 13 & 10 & 5 & 9 & 7 & 6 & 7 & 10 & 6 & 1 & 85 & $4 \%$ \\
\hline Guatemala & 1 & 3 & 2 & 2 & 0 & 2 & 1 & 1 & 3 & 3 & 0 & 0 & 18 & $1 \%$ \\
\hline Guiné Bissau & 6 & 5 & 2 & 3 & 2 & 6 & 2 & 5 & 4 & 0 & 0 & 4 & 39 & $2 \%$ \\
\hline Haiti & 0 & 0 & 0 & 0 & 0 & 1 & 0 & 4 & 3 & 1 & 0 & 1 & 10 & $0 \%$ \\
\hline Honduras & 1 & 1 & 0 & 0 & 0 & 0 & 0 & 1 & 0 & 0 & 1 & 0 & 4 & $0 \%$ \\
\hline Índia & 0 & 0 & 0 & 0 & 2 & 0 & 1 & 0 & 0 & 1 & 1 & 1 & 6 & $0 \%$ \\
\hline Jamaica & 0 & 0 & 0 & 0 & 0 & 0 & 0 & 1 & 0 & 0 & 0 & 0 & 1 & $0 \%$ \\
\hline México & 6 & 1 & 5 & 5 & 4 & 3 & 8 & 3 & 2 & 5 & 2 & 0 & 44 & $2 \%$ \\
\hline Moçambique & 12 & 16 & 12 & 9 & 3 & 8 & 21 & 24 & 52 & 49 & 51 & 22 & 279 & $12 \%$ \\
\hline Nicarágua & 0 & 0 & 1 & 0 & 2 & 0 & 3 & 0 & 1 & 0 & 1 & 2 & 10 & $0 \%$ \\
\hline Nigéria & 1 & 0 & 0 & 0 & 0 & 1 & 0 & 2 & 0 & 0 & 0 & 0 & 4 & $0 \%$ \\
\hline Panamá & 0 & 1 & 2 & 1 & 2 & 1 & 0 & 3 & 0 & 1 & 1 & 0 & 12 & $1 \%$ \\
\hline Paquistão & 0 & 0 & 0 & 0 & 0 & 0 & 0 & 0 & 0 & 0 & 1 & 0 & 1 & $0 \%$ \\
\hline Paraguai & 6 & 6 & 10 & 8 & 12 & 4 & 8 & 7 & 4 & 3 & 4 & 0 & 72 & $3 \%$ \\
\hline Peru & 6 & 21 & 25 & 27 & 33 & 20 & 36 & 32 & 34 & 23 & 15 & 8 & 280 & $12 \%$ \\
\hline Rep. D. Congo & 0 & 0 & 1 & 0 & 0 & 0 & 0 & 0 & 1 & 0 & 0 & 1 & 3 & $0 \%$ \\
\hline R. Dominicana & 1 & 0 & 1 & 2 & 4 & 1 & 0 & 1 & 1 & 0 & 0 & 0 & 11 & $0 \%$ \\
\hline S. T.Príncipe & 4 & 0 & 0 & 0 & 1 & 1 & 1 & 2 & 2 & 1 & 0 & 0 & 12 & $1 \%$ \\
\hline Senegal & 0 & 1 & 1 & 0 & 0 & 0 & 0 & 0 & 0 & 2 & 2 & 0 & 6 & $0 \%$ \\
\hline Tanzânia & 0 & 0 & 0 & 0 & 0 & 0 & 0 & 0 & 0 & 0 & 4 & 0 & 4 & $0 \%$ \\
\hline Togo & 0 & 0 & 0 & 0 & 0 & 0 & 0 & 0 & 0 & 0 & 1 & 0 & 1 & $0 \%$ \\
\hline Suriname & 0 & 0 & 0 & 0 & 0 & 0 & 0 & 1 & 0 & 0 & 0 & 0 & 1 & $0 \%$ \\
\hline Timor Leste & 6 & 0 & 11 & 14 & 16 & 6 & 6 & 3 & 0 & 6 & 3 & 0 & 71 & $3 \%$ \\
\hline T. e Tobago & 0 & 0 & 0 & 0 & 0 & 0 & 0 & 1 & 0 & 0 & 0 & 0 & 1 & 0\% \\
\hline Uruguai & 10 & 9 & 5 & 4 & 9 & 6 & 3 & 3 & 6 & 1 & 1 & 1 & 58 & $2 \%$ \\
\hline Venezuela & 1 & 2 & 0 & 1 & 2 & 1 & 6 & 5 & 3 & 2 & 1 & 1 & 25 & $1 \%$ \\
\hline Total por ano & 120 & 171 & 170 & 183 & 230 & 188 & 215 & 226 & 286 & 239 & 205 & 91 & 2324 & $100 \%$ \\
\hline
\end{tabular}




\section{(1) URI|}

Fonte: MRE, 2018.

No recorte temporal do ano de 2005 a 2016 percebe-se um destaque na participação dos países das Américas no PEC-PG, correspondendo a cerca de $75 \%$ do total de selecionados para o Programa, obtendo destaque a Colômbia com $28 \%$ dos selecionados, Peru correspondendo a $12 \%$ e Argentina que corresponde a $4 \%$. Ao contabilizar os selecionados provenientes da África, há uma porcentagem total em cerca de $20 \%$, obtendo destaque, Moçambique correspondendo a 12\%, Cabo Verde correspondendo a $6 \%$ e Guiné-Bissau correspondendo a 2\%. Tratando-se dos países Asiáticos, há uma representatividade total em cerca de 5\%, sendo que o Timor-Leste é um país de destaque, correspondendo a cerca de 3\% dos selecionados.

Nota-se um decréscimo da participação de países Asiáticos no Programa a partir do ano de 2010. Por sua vez, as participações de países da América Latina tiveram um crescimento na participação do Programa até o ano de 2013, mas de 2014 em diante houve um decréscimo geral da participação destes países. Já os países africanos tiveram um aumento significativo na participação dos selecionados para o Programa até o ano de 2015 e apresentou uma diminuição brusca nesta porcentagem no ano de 2016. Em sua última edição o Programa recebeu 596 candidaturas e foram concedidas 226 bolsas. Das 226 bolsas concedidas, 105 foram direcionadas ao mestrado e 121 para o doutorado (MRE, 2018).

Através de uma percepção geopolítica e ao que diz respeito aos governos que deram maior visibilidade à CSS, principalmente nos âmbitos da Pós-Graduação, percebe-se que mesmo com a queda de participação africana no Programa a partir do ano de 2016, percebe-se uma continuidade em relação à representatividade destes países, enquanto os países das Américas reduziram sua participação de modo sutil..

\section{CONCLUSÃO}

Esse estudo objetivou caracterizar e discutir elementos preliminares do Programa PEC-PG. Para tanto, realizou-se uma discussão sobre a internacionalização da Educação Superior, que aborda aspectos históricos passíveis de sustentar a compreensão dos processos e intenções da mesma. A partir de tal premissa foi realizada uma breve caracterização da 


\section{CIÊNCIAS HUMANAS}

REVISTA DO PROGRAMA DE PÓS-GRADUAĞ̈O EM EDUCAĞ̄o

\section{(10)URI|}

Cooperação Sul-Sul. Estas abordagens possibilitaram uma contextualização de forma a compreender aspectos preliminares das dinâmicas presentes no Programa PEC-PG.

Nesta perspectiva, a exploração de dados referentes ao Programa demonstra alguns resultados preliminares de análise. É possível perceber que no âmbito do Programa existe uma maior demanda pelas áreas de conhecimento que estão atreladas a técnicas e tecnologias que visam o mercado de trabalho. Porém, há uma maior variedade em áreas de conhecimento vinculadas às questões sociais, políticas e econômicas, mesmo que o número de ingressantes nestas áreas seja menor.

Quanto à Cooperação Sul-Sul em diálogo com o Programa, percebe-se que historicamente o PEC-PG tinha maior vínculo com os países da América Latina. Justifica-se tal fato a facilidade de acesso e intercâmbio entre estes países, além do fato de que a Cooperação Sul-Sul ainda aparecia de forma tímida em termos globais. A partir do ano de 2003, o governo brasileiro deu maior visibilidade à cooperação, gerando aproximação significativa com os países africanos numa perspectiva dialógica a partir de aspectos históricos e culturais.Frente ao exposto, destaca-se que o programa PEC-PG está diretamente vinculado as premissas e intenções da internacionalização da Educação Superior e das relações de interculturalidade, no Brasil apresenta a intenção de atuar junto ao fortalecimento dos países envolvidos. Porém, nota-se que o Brasil ocupou uma posição de destaque nesta cooperação, não só por ocupar espaços privilegiados, mas num contexto político específico, a partir de políticas públicas orientadas para tal fim.

\section{REFERÊNCIAS}

AMARAL, J. B. Atravessando o Atlântico: o Programa Estudante Convênio de Graduação e a cooperação educacional brasileira. 2013. Dissertação (Mestrado em Desenvolvimento, Sociedade e Cooperação Internacional) - Programa de Pós Graduação em Desenvolvimento, Sociedade e Cooperação Internacional. Universidade de Brasília, Brasília.

BOGDAN, R. C; BIKLEN, S. K. Investigação qualitativa em educação. Portugal, 1994.

BRASIL. Agencia Brasileira de Cooperação. In: Ministério das Relações Exteriores. Disponível em: http://www.abc.gov.br/SobreABC/Historico. Acesso em: jun/2017

BRASIL. Ministério das Relações Exteriores. Diretrizes para o desenvolvimento da cooperação técnica internacional multilateral e bilateral. 4. ed. Brasília, 2014. 


\section{CIÊNCIAS HUMANAS}

REVISTA DO PROGRAMA DE PÓS-GRADUAĞ̈O EM EDUCAĞ̄o

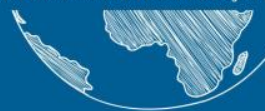

(10)URI|

BRASIL. Ministério das Relações Exteriores. Programa de Estudante-Convênio de Graduação - PEC-G. 2018 Disponível em:

http://www.dce.mre.gov.br/PEC/G/historico/introducao.php. Acesso em: abr/2018.

\section{CAPES. Manual do Programa Estudante-Convênio de Pós-Graduação (PEC-PG).}

Brasília, 2017. Disponível em: http://www.capes.gov.br/plano-nacional-de-pos-graduacao. Acesso em: abr/2018.

CHEDIEK. J. A Cooperação Sul-Sul O papel do Brasil na Cooperação Sul-Sul: um estudo analítico e histórico. In: ALMINO, J; LIMA, S. E. M. 30 anos da abc: visões da cooperação técnica internacional brasileira. Brasília: FUNAG, 2017. p. 41-71.

FEIJÓ, R. N. A internacionalização da educação superior no Brasil: um estudo de caso de alunos estrangeiros do Programa de Pós-Graduação em Antropologia Social/UFRGS. 2013.Dissertação (Mestrado em Educação) - Programa de Pós-Graduação em Educação da Universidade Federal do Rio Grande do Sul, Rio Grande do Sul.

GIL, A. C. Métodos e Técnicas de Pesquisa Social. 5. ed. São Paulo: Atlas, 1999.

IPEA - Instituto de pesquisa econômica aplicada. Cooperação brasileira para o desenvolvimento internacional: 2011 - 2013. Brasília: Ipea, 2016.

KNIGHT, J. Cinco verdades a respeito da internacionalização, 2012. Disponível em: https://www.revistaensinosuperior.gr.unicamp.br/international-higher-education/cincoverdades-a-respeito-da-internacionalizacao. Acessoem: jun/2017.

KNIGHT, J. Modèled'internationalisationou comment faire face aux réalités et enjeux nouveaux. In: OCDE. L'enseignementsupérieurenAmériquelatine: la dimension internationale. Paris: Organization de Coopération et de DéveloppementÉconomique, 2005. p. $11-45$.

LASTRES, H; ALBAGLI, S. Informação e globalização na era do conhecimento. Rio de Janeiro: Campus, 1999.

LIBERATO. E. A Formação de Quadros Angolanos no Exterior: Estudantes angolanos em Portugal e no Brasil. Caderno de Estudos Africanos. Lisboa. v. 23 p. 109-130, 2012.

MILANI, C.R. S; CONCEIÇÃO, Francisco Carlos da; M'BUNDE, Timóteo Saba. Cooperação Sul-Sul em Educação e Relações Brasil-PALOP. Caderno CRH, Salvador, v. 29, n. 76, p.13-32, jan. 2016. Semestral. Disponível em: <http://www.scielo.br/scielo.php?script=sci_arttext\&pid=S010349792016000100013\&ln $\mathrm{g}=\mathrm{en} \& \mathrm{nrm}=\mathrm{iso}$ Acesso em: jul/2017.

MOROSINI, M C. Estado do conhecimento sobre a internacionalização da Educação Superior. Educar. Curitiba, n. 28, p. 107-124, 2006.

MOROSINI, M C; NASCIMENTO, L M. Internacionalização da educação superior no brasil: a produção recente em teses e dissertações. Educação em Revista. Belo Horizonte, v. 33.

\begin{tabular}{c|c|c|c}
\hline Rev. Ciências Humanas & Frederico Westphalen, RS & Pg. 109-128 & Maio/Agosto 2019 \\
\hline Recebido em: 22/05/2019 & Aceito em: 04/06/2019 \\
\hline
\end{tabular}




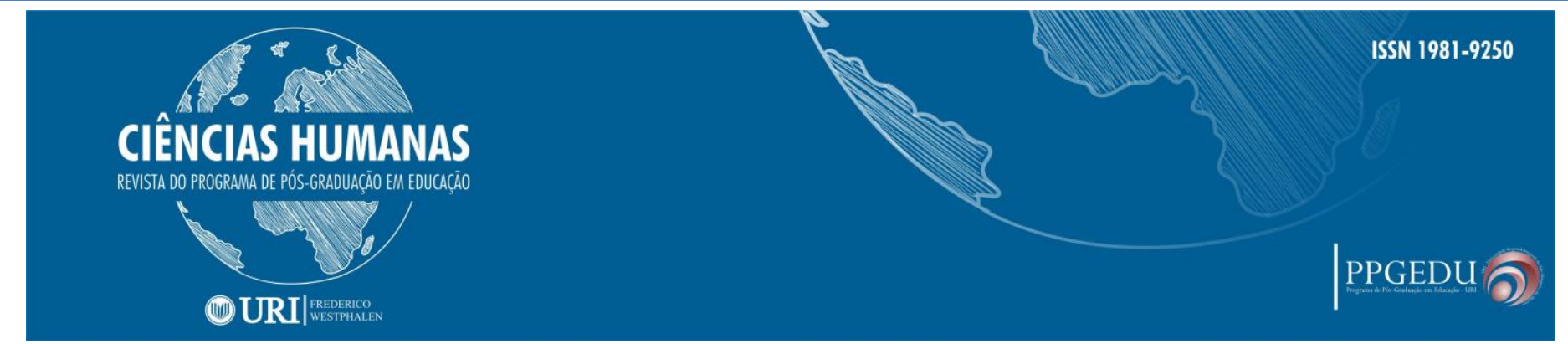

2017. Disponível em: http://www.scielo.br/scielo.php?script=sci_arttext\&pid=S01026982017000100109\&lng=en\&nrm=iso Acesso em: jul/2017

STALLIVIERI, Luciane. Estratégias de internacionalização das Universidades brasileiras. Caxias do Sul: EDUCS, 2004.

WIT, H. Repensando o conceito da internacionalização. Revista Ensino Superior, Campinas, fev. 2013. Disponível em: <http https://www.revistaensinosuperior.gr.unicamp.br/international-higher-education/repensandoo-conceito-da-internacionalizacao>. Acesso em: dez/2017. 